\title{
Mental Health Preparedness for Trauma Includes Addiction and Chronic Pain
}

\author{
Author: Diane Snow \\ DOI: $10.1080 / 10884600600599176$ \\ Publication Frequency: 4 issues per year \\ Published in: $\vee$ Journal of Addictions Nursing, Volume 17, Issue 1 December 2006 , pages 1 - \\ 3
}

\section{Introduction}

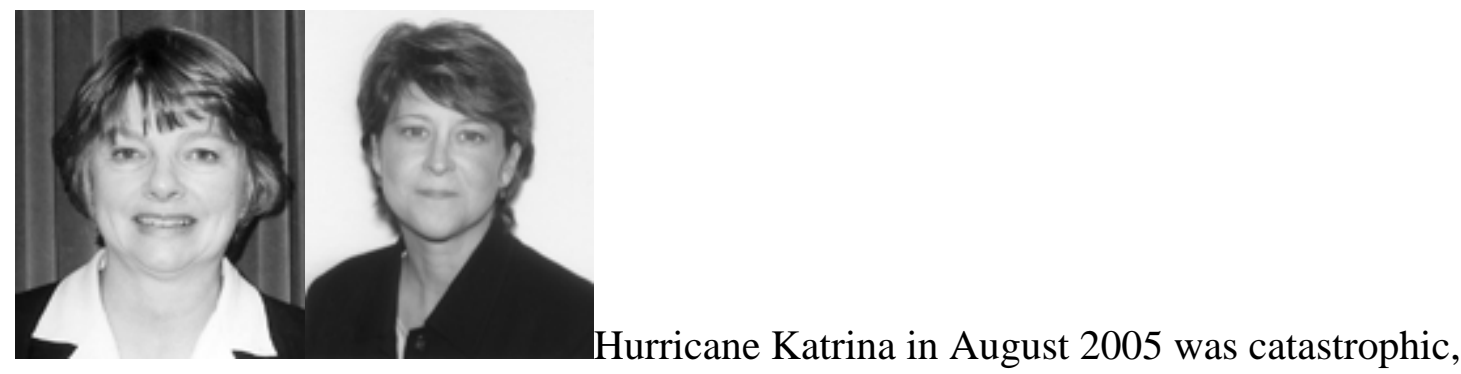
destroying the majority of the city of New Orleans and changing the lives of its people forever. Handling the evacuees was monumental and traumatic and required courage and faith. In reflecting back to August of 2005 and the subsequent weeks and months since that event, lessons have been learned and questions still linger. How do we mobilize volunteers and resources such as medical supplies and medications more efficiently in the future? How do we continue to help those who have been displaced who still need medical, legal and vocational services? What are we doing to prevent post-traumatic stress disorder and is it helping? And did we show enough compassion and provide care and ongoing services to those who needed it the most including addicts and those with chronic pain? These and other questions will be the topics of many ongoing discussions and relevant research projects.

No one could have been adequately prepared for the arrival of buses from the Superdome, the New Orleans Convention Center, and the bridges, to Texas six days after the hurricane. Bus after bus arrived in Dallas until Reunion Arena and the Convention Center were full and then the next buses were sent to the shelters in Fort Worth, Denton, Arlington and surrounding cities until every shelter was full. The same sequence of events happened in Houston, San Antonio and other locations. The evacuees were not told what city they were going to, and families were separated and spent weeks and months trying to find loved ones. The stories of atrocities including sexual abuse of children in the Superdome was confirmed as story after story was told by those held captive there. Among those who suffered as the city of New Orleans was destroyed by water were the drug addicts, those active in their addiction and those on methadone, as well as those in treatment programs and early recovery. 
What did we do right and wrong for those dealing with the pain of addiction in the shelters and camps for evacuees? Listening to their stories was the best thing we did, acknowledging and reinforcing their tremendous courage to survive. Many methadone patients were among the evacuees. Those who had been in the Superdome were told to bring 3 days worth of medicine, food and clothing with them. One woman was told to take her 3 days dosage of methadone all at once. When she arrived at the shelter, she was without her methadone for 5 days or more and was in full withdrawal. We praised her her courage for getting clean from heroin and offered her medication to ease the pain and craving. She was to return in an hour to see if the medication had arrived. Clonidine was not in the makeshift pharmacy so we wrote "FEMA" on the prescription and within 15 minutes it arrived. We could not find her as we searched through the thousands of individuals on cots and palettes to give her the medication sooner. We had a desk for people to sign up for mental health services but we didn't have methadone clinic sign ups ready, this came much later. Was she able to hold on without relapsing? Did she escape the reality of what had happened, and the emotional readjustment problems she would face as a result of the stress, and return to using drugs? (Volkow, 2006) Some shelters and camps were in communities without methadone clinics. They eventually were able to get methadone for their patients in the shelters. This took some time but was heralded as a success, if only for the short term. Today there is a website for anyone wishing to sign up for methadone treatment.

Was compassion shown for those in the shelters with a drug addiction who had been stranded on the bridges and other places in New Orleans? The loss of their homes and displacement coupled with the overcrowdoing in the shelters added to the tension and stress on relationships (SAMHSA, 2006). Was it surprising that they came by the medical "tent" frequently, sometimes every few hours, expressing pain, asking for anything they could get to relieve their symptoms, even cough syrup? Those with chronic pain were among the patients who suffered the most. Some did not even know what their medications were so were unaware of their dependence on narcotics. They only knew how much they were suffering from withdrawal type symptoms and their chronic pain condition. Unfortunately many volunteers did not understand the difference between addiction and dependence and were not prepared to deal with these patients. They called them addicts and were insensitive to their needs.

Services were set up on the internet and in the communities that have addiction treatment, but accessing those services was another issue when the shelters and camps were emptied, sometimes very suddenly, and evacuees were placed in hundreds of different hotels and other locations waiting for apartments to open up for them. They had not been given proper referrals and information for community services. Even getting a social security card became a major challenge in cities where there is less than adequate bus service. Some families bought cars with the $\$ 2000$ given to them by FEMA, but had no knowledge how to get around the cities and some did not even have drivers licenses. Community agencies such as Manpower Solutions were helpful but they were overloaded with requests. Others roamed the streets without any real direction.

One lesson learned was that the faith-based community is crucial to the success of recovery. Thousands of churches set up shelters in their parish halls, took families into their homes and helped the evacuees feel that they were cared for. Many churches recognized that they were struggling to deal with the mental health needs of the evacuees and sought out Psychiatric 
Mental Health Nurse Practitioners and other specialists to teach them how to handle various situations such as depression, suicidal thinking, drug abuse and symptoms of post-traumatic stress disorder. Other families were "adopted" by individuals and families, and became an anchor of hope for evacuees as they poured out their time, money and support to help them. Cell phones were purchased for families so that they could locate their loved ones and Christmas presents and apartment furnishings were provided. Many survivors expressed that life was better than it ever was in New Orleans, but they still had lost everything familiar to them. The relief efforts continue months and months after the traumatic event.

Another lesson learned is the strength of the family. Relatives opened up their apartment and houses to up to twenty or more displaced family members. And they received help from their friends, coworkers and church members who provided clothing, bedding, food and household goods. Being together as a family overcame many obstacles such as space and privacy. For those without a family, who had been living on the streets and addicted to drugs, would life be any better now?

There is no way of knowing at this time if these acts of kindness and generosity will help prevent post traumatic stress disorder. I am sure that those who were most traumatized while waiting to be rescued will be most vulnerable. They still need to tell their stories just like those who need to tell their stories about 9-11. They are waiting to be asked.

The mental health of everyone in the world has been affected at one level of another by the events of that August 2005 hurricane. Nurses, physicians and other health care providers volunteered their time to help where they could. And their lives were changed forever by the experience. Those of us with a specialty in psychiatry and addictions will continue to face the aftermath. We understand the relationship of stress and substance use and the risks to relapse even after years of abstinence in those in recovery from addiction (Volkow, 2006a) Just as we hear the stories about Vietnam in the veterans with post-traumatic stress disorder who alter their lives to avoid facing triggers to their trauma based symptoms, we will hear the "war stories" about Katrina for years to come. The Substance Abuse and Mental Health Services Administration (SAMHSA) promises to provide longer-term follow up care to address posttraumatic stress disorder in the hurricane survivors (SAMHSA, 2006). We need to tell our stories, too, so that we remember that we too are vulnerable, we work day after day with people with tremendous needs, and we have post-trauma responses as well. We learn to not absorb our patients' stories, to keep our lives in perspectives. Yet, the world is not the same without the special city of New Orleans.

We have learned lessons from Katrina that are life changing. We will never be the same. We learned that nurses and other health caire providers volunteer their time and energy when disaster strikes. We always knew that would be true. We learned that nurses and other health care providers are good listeners, yet they need education in addiction versus dependence especially regarding chronic pain. We learned that stigma is still an issue regarding addiction in many of our own professionals. We felt our own vulnerability and recognized our need for debriefing that was not always available. We learned that setting up a better continuity of care system would have prevented loss of contact when the evacuees were moved from place to place. And finally, we accept that many of those whose suppily of drugs was cut off due to the aftermath of the 
storm, and who came through the pain and suffering of withdrawal, have most likely returned to the streets in search of their drugs of choice. We hope mere are some who made a decision to get the help they need to begin recovery. We hope those who were on methadone did not relapse before they were able to get their medication, and that SAMHSA's promise to provide ongoing treatment for evacuees with chronic mental and addictive disorders and children with serious emotional disturbances (SAMHSA, 2006) will help relieve some of the burden caused by the storm's fury. We hope we made a difference, and pray that next time we are better prepared.

- Accept the reality of the loss.

- Allow yourself and other family members to feel sadness and grief over what has happened.

- Adjust to a new environment. Acknowledge that the person or possessions lost are gone forever.

- Put closure to the situation and move on. Do not continue to let the loss take its physical, emotional, or spiritual toll.

- Have faith in better times to come.

- When homes are destroyed or damaged, families may have to live in temporary housing or with relatives and friends, leading to overcrowding and added tension.

- Family members or friends may be forced to move out of the area, disrupting relationships and usual support systems.

\section{REFERENCES}

- 1. http://www.samhsa.gov/hurricane/default.aspx. - Substance Abuse and Mental Health Services Administration. SAMHSA's mission for hurricane Katrina. Available Jan. 20, 2006.

- 2. http://www.mentalhealth.sainhsa.gov/publications/allpubs/NMH02-0139/default.asp Substance Abuse and Mental Health Services Administration. Self-Care Tips for Survivors of a Traumatic Event: What to Expect in Your Personal, Family, Work, and Financial Life. Available Jan. 20, 2006.

- 3. http://www.drugabuse.gov/about/welcome/messagestress905.html - Volkow, N. (2006) The effects of stress on ding abuse. National Institute on Drug Abuse. Available Jan. 23, 2006.

- 4. http://www.drugabuse.gov/StressAL5rt/StressAlert.html - Volkow, N. (2006) NJDA community drug alert bulletin. National Institute on Drug Abuse. Available Jan. 20, 2006. 